\title{
Segurança hídrica no Brasil: situação atual, principais desafios e perspectivas futuras
}

Water security in Brazil: present situation, main challenges and future perspectives

ta de entrada: $11 / 01 / 2019$

Data de aprovação: 19/03/2019

Alessandra Campos dos Santos ${ }^{1 *}$ | Alan Reis ${ }^{1}$ | Eduardo Mario Mendiondo ${ }^{1}$

DOI: https://doi.org/10.36659/dae.2020.060

ORCID ID

Santos AC (iD https://orcid.org/0000-0002-9322-8391

Reis A iD https://orcid.org/0000-0002-0465-6563

Mendiondo EM (D) https://orcid.org/0000-0003-2319-2773

\section{Resumo}

A segurança hídrica consiste em garantir o acesso a água de qualidade e em quantidades suficientes para satisfazer o bem-estar das presentes e futuras gerações, bem como a manutenção dos ecossistemas. Esse tema está ganhando cada vez mais espaço entre os líderes mundiais e nas discussões ambientais, econômicas e sociais. Sendo um país de dimensões continentais, o Brasil apresenta regiões com características distintas, como clima, paisagens, densidade populacional e, consequentemente, diferentes problemas relacionados à segurança hídrica. Diante disso, esta revisão tem como objetivo principal caracterizar a situação atual da segurança hídrica no Brasil, indicar alguns desafios inerentes a esse tema e quais são as perspectivas possíveis para lidar com tais fatos. A metodologia consiste em caracterizar o país segundo algumas variáveis relacionadas à segurança hídrica, sendo: disponibilidade hídrica; demandas de água; captação e tratamento de esgoto; e gestão de recursos hídricos. Então, essas variáveis serão relacionadas a alguns desafios enfrentados no Brasil em relação à segurança hídrica. Por fim, são apresentadas perspectivas e recomendações para a implementação de ações visando à melhoria da segurança hídrica no Brasil.

Palavras-chave: Segurança Hídrica. Recursos Hídricos. Brasil. Gerenciamento. Usos da Água. Disponibilidade Hídrica. Mudanças Climáticas.

\section{Abstract}

Water security consists of guaranteeing access to quality water in sufficient quantities to ensure the well-being of present and future generations, as well as the maintenance of ecosystems. This theme is gaining more and more space among world leaders and in environmental, economic and social discussions. As a country with continental dimensions, Brazil presents regions with different characteristics, such as climate, landscapes, population density, and, consequently, different problems related to water security. Given this, this paper has as main objective to characterize the current situation of water security in Brazil, indicate some challenges inherent to this theme and what are the possible perspectives to deal with such facts. The methodology consisted of characterizing the country according to some variables related to water security, such as: water availability; water demands; sewage capture and treatment; and water resources management. Then, these variables will be related to some challenges faced in Brazil about water security. Finally, some perspectives and recommendations are presented for the implementation of actions aiming the improvement of water security in Brazil. Keywords: Water Security. Water Resources. Brazil. Management. Demands. Water Availability. Climate Changes.

\footnotetext{
${ }^{1}$ Escola de Engenharia de São Carlos - São Carlos - São Paulo - Brasil.

* Autora correspondente: s.c.aleahotmail.com.
} 


\section{INTRODUÇÃO}

A demanda por água continua crescendo em todo o mundo devido, principalmente, ao crescimento populacional, à industrialização, à agricultura, ao uso doméstico e à produção de energia (Srinivasan et al., 2013). Nesse contexto, a Organização das Nações Unidas para a Água propõe a seguinte definição de seguranÇa hídrica: "É o acesso sustentável à água em quantidades e qualidade aceitáveis para garantir o bem-estar das pessoas, o desenvolvimento socioeconômico e a preservação dos ecossistemas em um clima de paz e estabilidade política. Além disso, para garantir a proteção contra a poluição e outros desastres relacionados à água” (UN-Water, 2013).

A segurança hídrica lida diretamente com as pressões do crescimento urbano global e sua interferência nos recursos hídricos, o que, por sua vez, afeta a sustentabilidade e a proteção da saúde humana. As demandas futuras de água estão expostas a incertezas crescentes à medida que a escassez de água aumenta continuamente. Desta forma, a sociedade está cada vez mais suscetível aos riscos associados a demandas inadequadas de água e/ou qualidade diminuída (WHO, 2012).

O Brasil é um dos países mais ricos em recursos hídricos, respondendo por 12 a $14 \%$ de toda a água do mundo. No entanto, esse recurso não é uniformemente distribuído, uma vez que mais da metade está localizado na bacia Amazônica, uma região com baixa densidade demográfica. Por outro lado, apenas $1,6 \%$ da água encontrase no estado de São Paulo, onde vive um quarto da população do país (The World Bank, 2018).

Entre os anos de 2013 e 2014, a região Sudeste do Brasil sofreu uma intensa crise hídrica, causando prejuízos sociais, ambientais e econômicos para diferentes usuários de água. 0 Instituto de Meteorologia do Brasil mostrou que entre janeiro e março de 2014 só choveu $46 \%$ do esperado, com base nas médias históricas do período entre 1961-1990 (CEMADEN, 2015). Esses fatos contribuem para o aumento das incertezas sobre a real eficiência das ferramentas e planos de gestão dos recursos hídricos no Brasil.

Atingir segurança hídrica sustentável exigirá a superação de desafios como mudanças climáticas, mudanças no uso e cobertura da terra, crescimento da população, aumento da demanda, entre outros. $E$ tudo isso englobando os níveis socioambiental e econômico. Assim, essa revisão tem como principal objetivo caracterizar a situação atual da segurança hídrica no Brasil, segundo algumas variáveis: disponibilidade hídrica; demandas de água; captação e tratamento de esgoto; e instituições responsáveis pela gestão da água. Em seguida, indicar os principais desafios inerentes a este tema e quais as possíveis perspectivas para lidar com tais fatos (Fig. 1). 


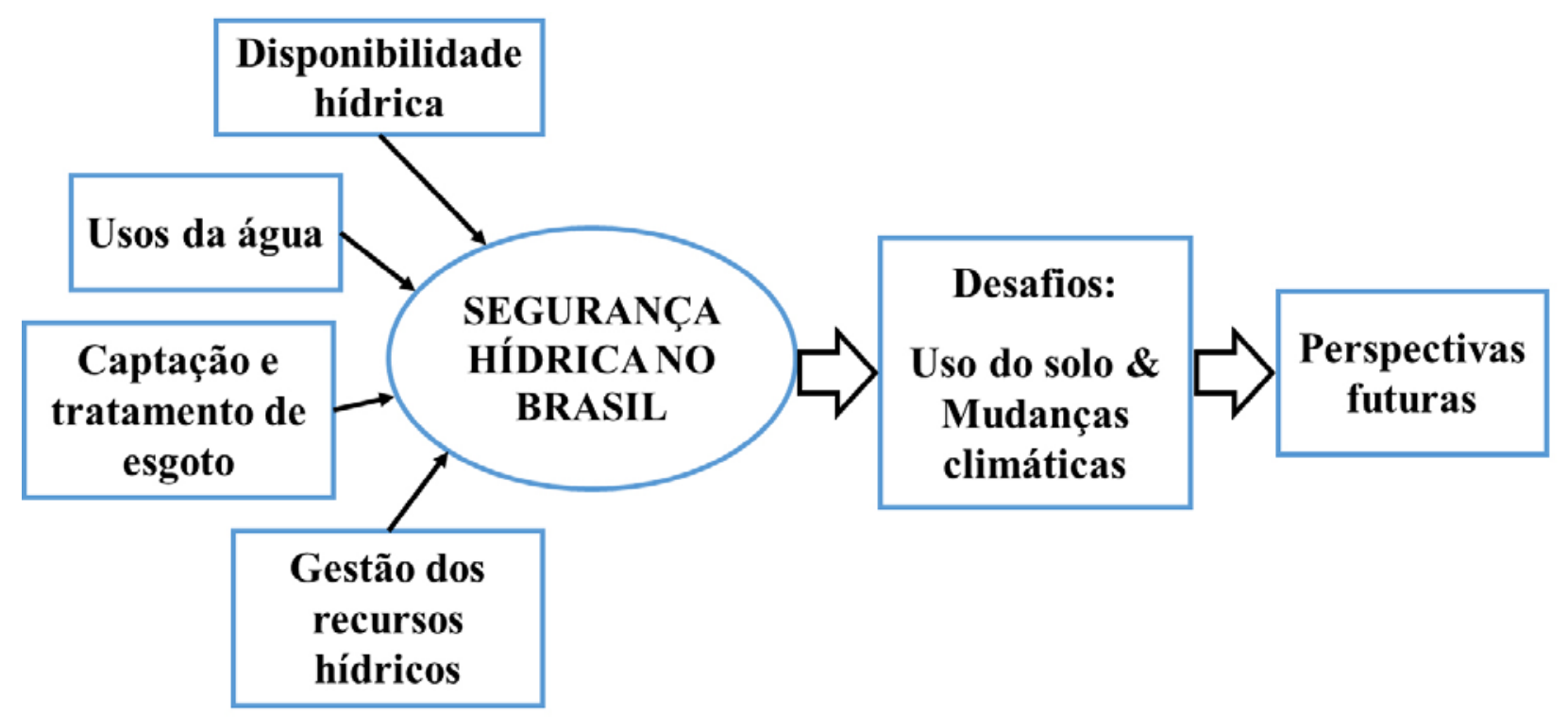

Figura 1. Fluxograma metodológico da pesquisa

\section{METODOLOGIA}

\subsection{Disponibilidade hídrica superficial}

O Brasil é dividido em 12 regiões hidrográficas (Fig. 1). O país possui alta disponibilidade de água superficial, correspondente a $78.600 \mathrm{~m}^{3} / \mathrm{s}$ ou $30 \%$ da vazão média. Contudo, esse recurso não é distribuído igualmente em todo o território. A região hidrográfica Amazônica ocupa $45 \%$ do território brasileiro, sendo a maior bacia do mundo e contribuindo com aproximadamente $83,5 \%$ da disponibilidade total de águas superficiais no Brasil. No entanto, essa região abriga a menor parcela da população $(4,5 \%)$ e consequentemente, a demanda de água é menor. Por outro lado, a região hidrográfica do Paraná é a mais populosa, totalizando $32 \%$ da população brasileira, além de cobrir 1.505 municípios, incluindo importantes centros populacionais como São Paulo, Brasília, Curitiba, Goiânia, Campinas, Campo Grande e Uberlândia. (ANA, 2017a).

Por se tratar de um país de dimensões continentais, o Brasil apresenta regiões com características diferentes. O Nordeste, mais especificamente a região semi-árida, apresenta naturalmente baixas taxas de precipitação durante o ano, precipitação anual inferior à média nacional, altas temperaturas e períodos prolongados de seca. O semi-árido cobre parte das regiões hidrográficas do Parnaíba, Atlântico Leste, São Francisco e Atlântico Nordeste Oriental (ANA, 2018a). Esta última apresenta a menor disponibilidade hídrica superficial do Brasil, $218 \mathrm{~m}^{3} / \mathrm{s}$ (Fig. 2). 


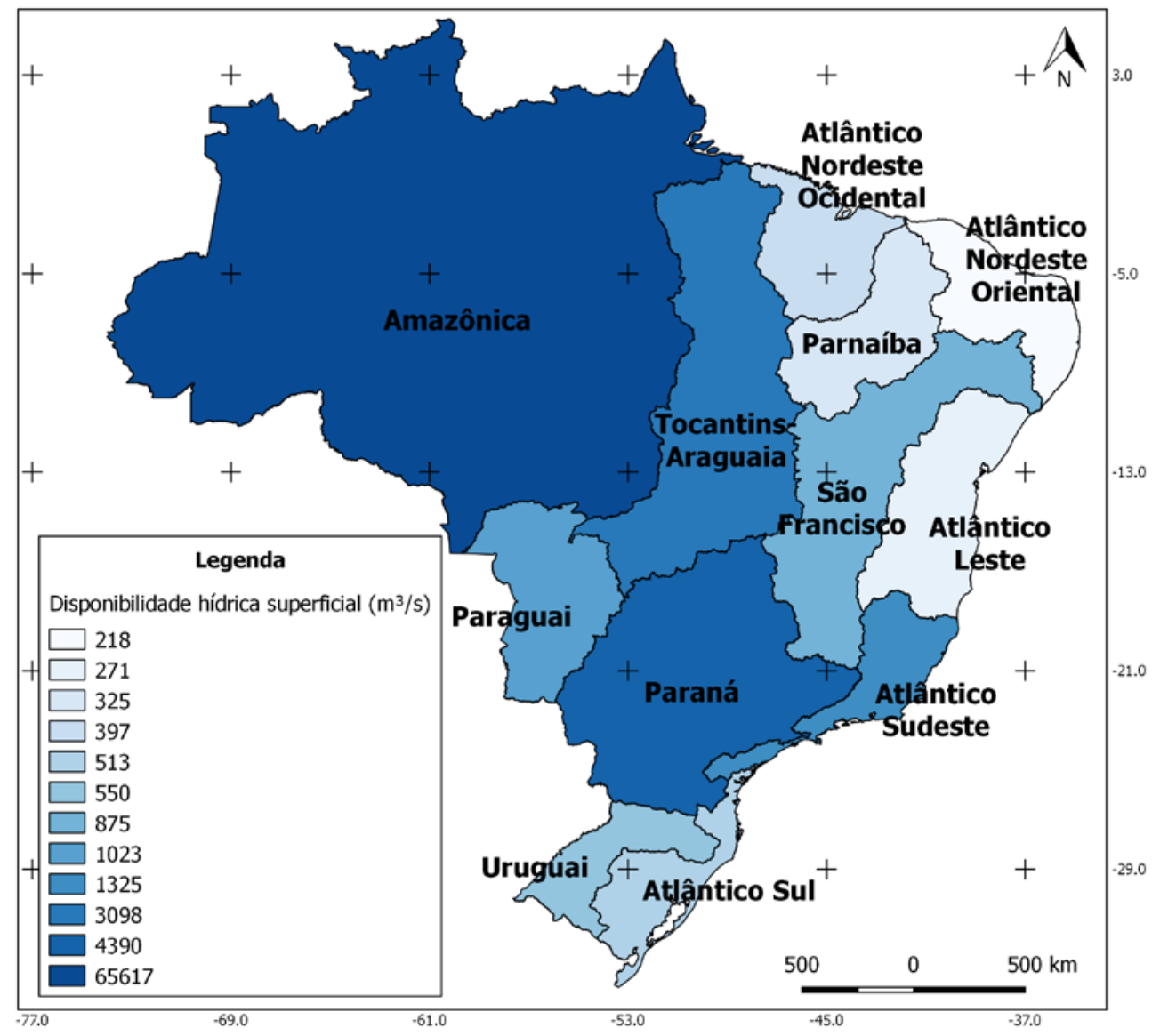

Figura 2. Disponibilidade hídrica superficial nas regiões hidrográficas brasileiras Fonte: Adaptado de ANA (2017a)

Incertezas quanto à disponibilidade hídrica, maior frequência de eventos climáticos extremos e fluxos de retorno mais rápidos da água para a atmosfera são esperados no futuro. Mudanças no ciclo hidrológico, como resultado do uso da terra e mudanças climáticas, e a natureza fechada de muitas bacias hidrográficas, alocações e padrões de uso futuro da água, serão diferentes das tendências passadas (Cosgrove; Loucks, 2015).

\subsection{Demandas de água}

O gráfico da Fig. 3 mostra as principais demandas de água no Brasil nos anos de 2006, 2010 e 2016. Observa-se que o principal uso é aquele destinado à irrigação, apresentando valores elevados em todos os anos analisados. De 2006 a 2010, todas as demandas aumentaram, com exceção do abastecimento rural. Isso ocorre porque o país está cada vez mais urbanizado e as populações rurais estão diminuindo ao longo do tempo. De 2010 a 2016, as demandas por irrigação, abastecimento urbano e uso industrial diminuíram. Esse fato pode ser explicado devido à crise hídrica que ocorreu em várias regiões brasileiras durante esse período.

Entre os anos de 2013 e 2014, a formação de uma zona de alta pressão atmosférica bloqueou a chegada da frente de ar da Amazônia, do Atlântico Sudeste e do Polo Sul, alterando o clima da região. As chuvas não chegaram à região Sudeste do Brasil, onde está localizada a maior cidade da América do Sul, São Paulo. Com a falta de chuvas, São Paulo e municípios vizinhos ficaram dependentes 
da água dos reservatórios. No final de janeiro de 2015, o principal reservatório da cidade, o Sistema Cantareira, passou a operar com apenas 7\% de sua capacidade (Millington, 2018).

Para compensar o baixo nível do Sistema Cantareira, a Companhia de Água e Saneamento do Estado de São Paulo (Sabesp) começou a utilizar água de outros reservatórios da região metropolitana de São Paulo. Outra medida adotada foi a redução da pressão nos tubos para minimizar os vazamentos, tendo como efeito colateral o aumento da frequência de escassez de água em alguns domicílios. Além disso, os consumidores que economizaram pelo menos $20 \%$ de seu consumo médio receberiam um desconto de $30 \%$ em sua conta de água (Kelman, 2015).

Em 2015, a seca na região Sudeste representou pelo menos $30 \%$ da crise econômica do país, já que o estado de São Paulo garante uma grande participação nacional. $O$ setor industrial sofreu uma queda na produção e redução de investi- mentos devido ao racionamento de água no estado (Martins, 2015). O setor hidrelétrico do país, durante o ano de 2015, teve uma escassez de usinas hidroelétricas em operação, mitigando o problema com a realocação de energia de outros polos (RenewPower, 2014).

Os problemas relacionados ao abastecimento de água no Brasil vêm principalmente de uma combinação de fatores, como industrialização, expansão das atividades agrícolas e crescimento urbano sem planejamento. Esses fatores contribuem para o crescimento excessivo da demanda local, o que pode levar ao esgotamento dos recursos hídricos, tanto em termos de qualidade como de quantidade (Veiga; Magrini, 2013). Espera-se que essa demanda aumente em mais de $50 \%$ até 2050 em comparação com o ano de 2015 (Ferroukhi et al., 2015). A necessidade e, consequentemente, a competição por água, energia e alimentos também aumentará (Cosgrove; Loucks, 2015).

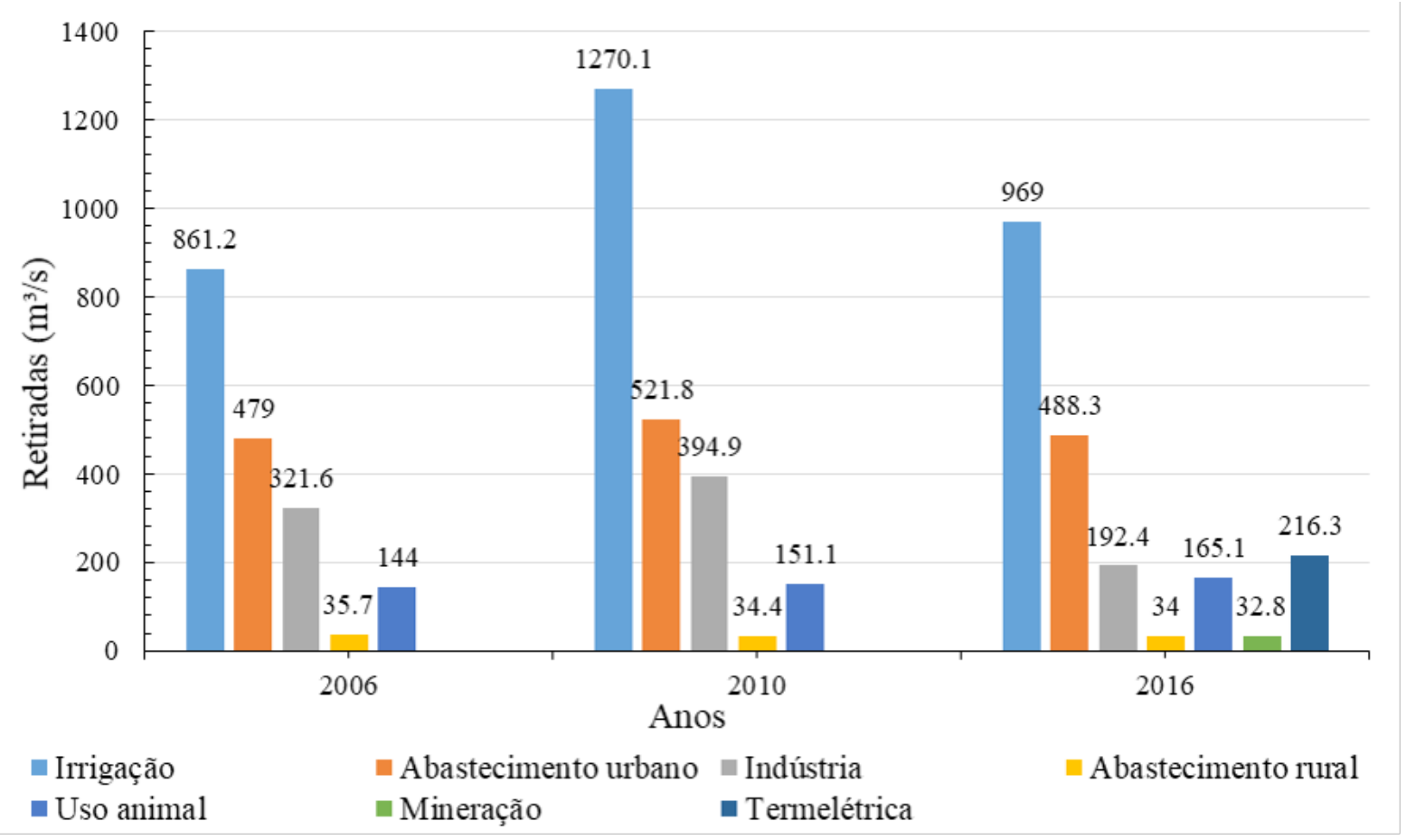

Figura 3. Usos da água no Brasil (2006, 2010 e 2016) Fonte: Adaptado de ANA (2009; 2013; 2017a) 
Todos os setores da economia usam a água de diferentes maneiras, assim a demanda nem sempre muda da mesma forma que o preço (Simão e Silva, 2009). Essa relação entre demanda e preço é definida como a elasticidade de preço da demanda e pode ser entendida como a medida entre a variação percentual de uma demanda em resposta a uma variação percentual no preço da água. Essa relação verifica em quanto o consumidor estaria disposto a reduzir o consumo de água em caso de aumento de preço. Se a elasticidade for maior que 1, a demanda é elástica, ou seja, um aumento no preço da água acarreta uma redução na demanda. Se a elasticidade for menor que 1, a demanda é inelástica, ou seja, um aumento no preço da água não causará uma redução proporcional na demanda. E finalmente, a demanda é unitária quando qualquer mudança no preço da água leva a uma mudança proporcional na demanda (Ribeiro, Lanna, Pereira, 1999).

Nesse contexto, a Agência Nacional de Energia Elétrica (ANEEL) criou em 2015 um mecanismo para tentar reduzir o consumo de eletricidade no Brasil, aumentando o teto de energia denominado Bandeiras Tarifárias. As tarifas variam de verde, amarelo e vermelho, e indicam se haverá ou não um aumento na quantidade de energia a ser repassada ao consumidor final, dependendo das condições de geração de eletricidade. A bandeira verde representa condições favoráveis de geração de energia, assim, a tarifa não aumenta. A bandeira amarela significa condições de geração menos favoráveis, levando a um pequeno aumento. $\mathrm{E}$ a bandeira vermelha indica condições mais caras de geração, sofrendo um aumento maior na conta dos consumidores (ANEEL, 2018).

Uma auditoria realizada pelo Tribunal de Contas da União (TCU) concluiu que as Bandeiras Tarifárias não geram consumo consciente, pois não levam a uma redução da demanda de energia no Brasil. Assim, de acordo com o relatório, as bandeiras não cumprem os objetivos para os quais foram criadas. Com esses resultados, o TCU determinou que a ANEEL elaborasse e publicasse relatórios mensais com as informações necessárias para verificar os dados e valores que subsidiavam a tarifa do respectivo mês (TCU, 2018).

\subsection{Coleta e tratamento de esgoto}

A Agenda 2030 para o Desenvolvimento Sustentável, adotada por todos os Estados-Membro das Nações Unidas em 2015, consiste em 17 objetivos. Neste contexto, destaca-se o 60: "Garantir disponibilidade e gestão sustentável de água e saneamento para todos". Ele diz, entre outras coisas, que até 2030 deve haver acesso a saneamento adequado e equitativo e higiene para todos; melhora na qualidade da água, reduzindo à metade a proporção de águas residuais não tratadas e aumentando substancialmente a reciclagem e a reutilização seguras em nível global (ONU, 2018).

A Lei $n^{0} 11.445$ de 5 de janeiro de 2007, ou Lei Brasileira de Saneamento Básico, estabelece as diretrizes nacionais para o saneamento básico e para a Política Federal de Saneamento Básico. Determina que os serviços públicos de saneamento devem ser realizados de maneira adequada à saúde pública e à proteção do meio ambiente, além de instituir o acesso universal a esses serviços (Brasil, 2007).

O esgoto sanitário - despejo líquido composto por esgoto doméstico e industrial, infiltração de água e chuva parasitária - é um dos serviços de saneamento que mais necessitam de atenção, análise e soluções adequadas, principalmente no que se refere ao gerenciamento da água. A baixa taxa de coleta e tratamento de esgoto em várias regiões do Brasil (Tabela 1) contribui para a geração de cargas poluidoras, causando prejuízos na qualidade dos recursos hídricos e, consequentemente, prejuízos aos múltiplos usos da água (ANA, 2017b). 
Como visto na Tabela 1, as taxas de coleta são baixas na maioria das regiões brasileiras. O Sudeste tem a maior taxa de coleta, equivalente a $83 \%$. A região Norte coleta apenas $16 \%$ do esgoto. 0 cenário se agrava quando o assunto é o tratamento. Nenhuma região brasileira trata todo o esgoto que é coletado; pelo contrário, as taxas de tratamento são baixas. Na região Sudeste, por exemplo, onde $83 \%$ do esgoto é coletado, apenas $54 \%$ passam pela etapa de tratamento. 0 cenário geral do Brasil consiste em $61 \%$ do esgoto coletado, em que apenas $43 \%$ recebe tratamento antes do despejo nos corpos d'água (ANA, 2017b).
A Associação Brasileira de Engenharia Sanitária e Ambiental (ABES) realizou um estudo denominado "Ranking 2018 da Universalização do Saneamento", em que 1.894 (de 5.570) municípios brasileiros foram analisados em relação ao saneamento básico. Destes, $85 \%$ do total ainda estão longe de fornecer saneamento básico para toda a população. Os únicos municípios que receberam nota máxima, tendo atingido $100 \%$ da população em todos os serviços de saneamento básico, foram São Caetano do Sul, Piracicaba, Santa Fé do Sul e Uchoa, todos localizados no estado de São Paulo (ABES, 2018).

Tabela 1. Geração e tratamento de esgoto nas regiões do Brasil

\begin{tabular}{|c|c|c|c|}
\hline \multirow{2}{*}{ Região } & $\begin{array}{c}\text { População urbana } \\
\text { (hab) }\end{array}$ & Coleta de Esgoto (\%) & Tratamento de Esgoto (\%) \\
\cline { 3 - 4 } & 12.667 .400 & 16 & 12 \\
\hline Norte & 40.817 .400 & 43 & 32 \\
\hline Nordeste & 77.285 .000 & 83 & 54 \\
\hline Sudeste & 24.432 .100 & 54 & 40 \\
\hline Sul & 13.283 .800 & 51 & 49 \\
\hline Centro-Oeste & 168.485 .700 & 61 & 43 \\
\hline Brasil & \multicolumn{2}{|c|}{ Fonte: Adaptado de ANA (2017b) } \\
\hline
\end{tabular}

Fonte: Adaptado de ANA (2017b)

No Brasil, o déficit na coleta e no tratamento de esgoto atinge principalmente as populações mais pobres que vivem, em geral, nas favelas, nas periferias dos centros urbanos e nas áreas rurais. A falta ou ineficiência desse serviço tem consequências negativas na saúde e na qualidade de vida das pessoas. Assim, investimentos insuficientes no setor de coleta e tratamento de esgoto podem afetar o sistema econômico, uma vez que os gastos com doenças propagadas devido a condições sanitárias inadequadas tendem a ser altos (Santos et al., 2018).

\subsection{Gestão dos recursos hídricos}

A primeira legislação criada para lidar com a apropriação e o uso da água no Brasil foi o Decreto Federal $n^{\circ} 24.643$ de 1934 . Foi promulgado em um contexto nacional de modernização e desenvolvimento econômico, em que a água era considerada um bem em abundância (ANA, 2017a). A gestão de recursos hídricos evoluiu consideravelmente com a promulgação da Lei $n^{\circ}$ 9.433. Essa lei foi baseada no modelo de gestão de recursos hídricos da França e trouxe mudanças relevantes nos aspectos administrativos, legais e institucionais dos recursos hídricos brasileiros (Veiga; Magrini, 2013).

A Lei no 9.433, de 8 de janeiro de 1997, estabeleceu a Política Nacional de Recursos Hídricos ou Lei das Águas - e criou o Sistema Nacional de Gerenciamento de Recursos Hídricos (SINGREH). O principal objetivo do SINGREH é gerenciar os usos da água de forma democrática e participativa: coordenar a gestão integrada dos recursos hídricos; arbitrar administrativamente conflitos relacionados a recursos hídricos; planejar, regular e controlar o uso, bem como restaurar corpos 
d'água; e promover a cobrança pelo uso da água (Brasil, 1997). A composição federal do SINGREH e suas principais atribuições estão detalhadas na

Tabela 2.

Tabela 2. Instituições federais brasileiras de gestão dos recursos hídricos

\begin{tabular}{|c|c|}
\hline Órgãos Gestores Federais & Principais Atribuições \\
\hline Agência Nacional de Águas (ANA) & Agência reguladora. Responsável pela implementação dos instrumentos de política. Poder outorgante. \\
\hline Comitê de Bacia & $\begin{array}{l}\text { Organismo colegiado. Responsável pela formulação da política; aprovação do Plano de Recursos } \\
\text { Hídricos da Bacia; arbitrar conflitos pelo uso da água; estabelecer mecanismos e sugerir os valores da } \\
\text { cobrança pelo uso da água; entre outros. }\end{array}$ \\
\hline Agência de Bacia & $\begin{array}{c}\text { Secretaria executiva do Comitê de Bacia. Responsável pela implementação dos instrumentos de } \\
\text { política. }\end{array}$ \\
\hline $\begin{array}{l}\text { Conselho Nacional de Recursos Hídricos } \\
\text { (CNRH) }\end{array}$ & $\begin{array}{l}\text { Organismo colegiado. Responsável pela formulação da política. Ocupa a instância mais alta na } \\
\text { hierarquia do Sistema Nacional de Gerenciamento de Recursos Hídricos. }\end{array}$ \\
\hline $\begin{array}{l}\text { Secretaria de Recursos Hídricos e Ambiente } \\
\text { Urbano (SRHU/MMA) }\end{array}$ & $\begin{array}{c}\text { Administração direta. Responsável pela formulação da política. Subsidiar a formulação do Orçamento } \\
\text { da União. }\end{array}$ \\
\hline Órgãos Gestores Estaduais & $\begin{array}{l}\text { Responsáveis pela fiscalização dos recursos hídricos e processos de outorgas nas respectivas Unidades } \\
\text { Federativas brasileiras. }\end{array}$ \\
\hline
\end{tabular}

A União é responsável pela gestão dos rios federais, isto é, aqueles que passam por mais de um estado brasileiro ou por território estrangeiro. Nos outros rios, cada estado tem sua própria política de água dentro de seus limites (Veiga; Magrini, 2013).

\section{PRINCIPAIS DESAFIOS PARA ASSEGURAR A SEGURANÇA HÍDRICA NO BRASIL}

\subsection{Mudanças climáticas}

As tendências demográficas, econômicas e tecnológicas aceleraram a capacidade do homem de mudar consciente e inconscientemente a natureza. Os seres humanos são os principais responsáveis por promover mudanças no meio ambiente. As ações antrópicas estão afetando cada vez mais o ambiente global, incluindo o clima da Terra. Essas mudanças influenciam as quantidades e distribuições espaciais e temporais da precipitação que cai nas bacias hidrográficas e, consequentemente, os processos hidrológicos, como os escoamentos e a infiltração (Cosgrove; Loucks, 2015). As mudanças climáticas também afetam a biodiversidade, forçando-a a se adaptar, seja mudando o habitat, o ciclo de vida ou até mesmo desenvolvendo novos traços físicos (CBD, 2018).

As mudanças climáticas e suas possíveis consequências são cada vez mais reconhecidas como uma questão prioritária nas discussões ambientais globais. De acordo com o quinto relatório de avaliação do Painel Intergovernamental sobre Mudanças Climáticas (IPCC), as emissões antrópicas de gases do efeito estufa são uma das principais causas das mudanças climáticas nos últimos anos. Essas mudanças aumentaram de 0,7 a $0,8^{\circ} \mathrm{C}$ na temperatura nos trópicos desde 1950. As previsões futuras também mostram um aumento na temperatura dos trópicos, de 1 a $2^{\circ} \mathrm{C}$ em 2050 e de 2 a $5^{\circ} \mathrm{C}$ em 2100 . Além disso, o relatório do IPCC reafirma a responsabilidade humana pelo aquecimento global e a urgência de adotar medidas e estratégias de mitigação e adaptação diante das consequências dessas mudanças (IPCC, 2013).

O Brasil é responsável por 3,4\% das emissões globais de gases do efeito estufa (a sétima maior do mundo). De acordo com o Sistema de Estimativa de Emissão e Remoção de Gases de Efeito Estufa (SEEG), em 2016 foram emitidos 2.277 milhões de toneladas de $\mathrm{CO}_{2}$ equivalentes (emissões bru- 
tas totais). Esse valor é dividido entre os setores de energia (18,6\%), agricultura (21,9\%), mudança de uso da terra e florestas $(51,3 \%)$, processos industriais $(4,2 \%)$ e tratamento de resíduos (4\%). Por outro lado, 529 mil toneladas de $\mathrm{CO} 2$ equivalente foram retiradas de florestas em áreas protegidas (61\%), florestas secundárias (18\%) e uso da terra (21\%) (SEEG, 2018).

A água é o principal recurso por meio do qual os efeitos das mudanças climáticas serão sentidos. Temperaturas mais altas e condições climáticas extremas e imprevisíveis afetarão os processos hidrológicos e a qualidade da água. Pessoas de baixa renda, que já são mais vulneráveis a qualquer ameaça ao abastecimento de água, provavelmente serão as mais afetadas (UN-Water, 2018).

\subsection{Mudanças no uso do solo}

Mudanças no uso do solo, devido principalmente ao crescimento populacional, à produção de alimentos, à geração de energia e ao movimento de pessoas aos centros urbanos, contribuem para afetar a quantidade e a qualidade dos recursos de água doce dos quais os seres humanos dependem para sobreviver, tanto física como economicamente. A água participa da criação de tudo o que é produzido no planeta. Não há substitutos e, embora seja renovável, há apenas uma quantidade finita dela (Cosgrove; Loucks, 2015).

O Instituto Brasileiro de Geografia e Estatística (IBGE) realizou um estudo intitulado "Mudanças na Cobertura e Uso da Terra no Brasil", com o objetivo de verificar mudanças no uso da terra entre os anos de 2000 e 2014, utilizando imagens de alta resolução, mapas temáticos e outros materiais cartográficos. $O$ estudo concluiu que as atividades agrícolas tiveram um grande aumento ao longo dos anos. As áreas de agricultura foram ampliadas em 16 milhões de hectares (40\%). As áreas de pastagem aumentaram 38 milhões de hectares (61,2\%), e as áreas de silvicultura cresceram 3 milhões de hectares (55,9\%). 0 estudo também notou a redução de quase $10 \%$ das áreas florestais, o equivalente a 33,8 milhões de hectares, entre 2000 e 2014 (IBGE, 2017).

Em 2016, o Brasil foi o segundo maior produtor de soja, o terceiro maior produtor de milho e o nono maior produtor de arroz do mundo. 0 agronegócio corresponde por mais de 30\% do total das exportações do país (FAO, 2018). Da Silva et al. (2016) analisaram os fluxos de água virtuais associados ao comércio internacional das principais commodities agrícolas brasileiras entre 1997 e 2012. Verificaram que o Brasil tem uma exportação bruta de água virtual de 67,1 bilhões de $\mathrm{m}^{3} / a n o$ e uma exportação líquida de 54 bilhões de $\mathrm{m}^{3}$ /ano de commodities agrícolas, principalmente para a Europa (41\%). O comércio virtual de água por meio de commodities, como safras que consomem muita água na produção, faz com que os países que importam esses produtos economizem água. No entanto, os países exportadores virtuais, como o Brasil, acabam pressionando seus recursos hídricos e podem contribuir para aumentar a insegurança em algumas regiões do país.

Além das práticas agrícolas, a produção de energia também contribui para a geração de mudanças no uso da terra. A geração de energia no Brasil está intimamente ligada à água. Exemplos de consumo de água para produzir energia incluem geração de energia hidrelétrica e o biocombustível.

A energia hidrelétrica é a principal fonte de energia no Brasil, correspondendo a 67,9\% em 2017 (Brasil, 2017). A construção de reservatórios de água para produção de energia pode levar a impactos ambientais negativos, como mudanças na qualidade da água, realocação de pessoas, mudanças na estrutura da comunidade aquática, perda de herança genética (flora e fauna), de- 
sestabilização de taludes e mudanças climáticas (Sperling, 2012).

Assim como a geração hidrelétrica, o uso de biocombustível também está crescendo no Brasil. O país é o maior produtor mundial de cana-deaçúcar, sendo o estado de São Paulo responsável por $55 \%$ da área plantada no país e o maior produtor mundial de etanol de cana-de-açúcar, contribuindo para que o Brasil seja o segundo maior produtor de etanol do mundo, atrás apenas dos Estados Unidos (Invest-SP, 2018).

Muitas das preocupações de sustentabilidade da bioenergia estão relacionadas à mudança direta ou indireta no uso da terra resultante da produção de matérias-primas de bioenergia (Hilst et al., 2018). A cana-de-açúcar é uma cultura de bioenergia comumente cultivada em regiões tropicais. $\mathrm{O}$ aumento da demanda por energia renovável levou a uma considerável expansão e intensificação das áreas agrícolas destinadas à produção de cana-de-açúcar no Brasil (Bento et al., 2018).

As culturas de biocombustíveis requerem grandes quantidades de recursos hídricos e terrestres, que poderiam ser utilizados para outros fins, como produção de alimentos e abastecimento de água. Como os recursos hídricos do Brasil não estão igualmente distribuídos entre as regiões, o crescimento da produção de etanol deve considerar a disponibilidade de água, para que não haja mais pressões sobre esse recurso, especialmente na região Sudeste do Brasil, que experimentou uma crise hídrica anos atrás (Castillo et al., 2017).

\section{PERSPECTIVAS FUTURAS PARA A SEGURANÇA HÍDRICA NO BRASIL}

Garantir o abastecimento de água para o consumo humano e para as atividades produtivas e reduzir os riscos associados a eventos críticos (secas e enchentes) são objetivos que estão incluídos nas questões abordadas no atual conceito de segurança hídrica. O planejamento e a implantação de infraestrutura hídrica adequada, vinculada a sistemas que operam a partir de uma gestão integrada de riscos, com foco na otimização do uso e armazenamento de água, são medidas necessárias que devem ser adotadas pelo setor de recursos hídricos (ANA, 2017a).

Como mencionado anteriormente, um dos Objetivos de Desenvolvimento Sustentável das $\mathrm{Na}$ ções Unidas é "Garantir a disponibilidade e gestão sustentável da água e do saneamento para todos" e, em resumo, tem os seguintes objetivos:

1. Alcançar o acesso universal e equitativo a água potável segura e acessível a todos;

2. Alcançar o acesso a saneamento e higiene adequados e equitativos para todos;

3. Melhorar a qualidade da água, reduzindo a poluição, eliminando o despejo e minimizando a liberação de produtos químicos e materiais perigosos;

4. Aumentar substancialmente a eficiência do uso da água em todos os setores e garantir retiradas e fornecimento sustentáveis;

5. Implementar a gestão integrada de recursos hídricos em todos os níveis;

6. Proteger e restaurar ecossistemas relacionados com a água;

7. Expandir a cooperação internacional e o apoio à capacitação para os países em desenvolvimento em atividades e programas relacionados à água e saneamento;

8. Apoiar e fortalecer a participação das comunidades locais na melhoria da gestão de água e saneamento (UN, 2018). 
Como pode ser visto, ainda há um longo caminho a percorrer antes de atingir todos esses objetivos, especialmente em relação à coleta e tratamento de esgoto, que, como visto anteriormente, ainda são precários em várias regiões do Brasil.

O Plano Nacional de Saneamento Básico (PLAN$\mathrm{SAB})$, desenvolvido pelo antigo Ministério das Cidades do Brasil, estimou a necessidade de investimentos em abastecimento de água potável e esgotamento sanitário nas áreas urbanas e rurais do Brasil entre o ano base de 2014 e os anos de 2018, 2023 e 2033. O plano indica a necessidade de investimento de $R \$ 122.149$ milhões no setor de abastecimento de água até 2033 e de $\mathrm{R} \$ 181.893$ milhões no setor de esgotamento sanitário até 2033. Desse total, 94,5\% são investimentos em áreas urbanas (PLANSAB, 2013).

Esses investimentos se justificam pela necessidade de ampliar a produção e a distribuição de água, que consiste na expansão ou implantação de redes de captação, adução, tratamento, reserva, distribuição, estações elevatórias, dispositivos de controle de pressão e conexões prediais. E também a expansão da coleta e tratamento de esgoto, que se caracteriza pela instalação de conexões prediais e pela implantação de sistemas de redes coletoras, interceptores, emissários, estações elevatórias e unidades de tratamento (PLANSAB, 2013).

Sobre as mudanças climáticas, o relatório do IPCC indicou que haverá mudanças no ciclo hidrológico devido ao aumento da intensidade e à variabilidade dos eventos de precipitação, que podem afetar a disponibilidade e a distribuição temporal do fluxo nos rios. Sendo um país de grandes extensões, o Brasil deve sofrer efeitos diferenciados de acordo com a região, como a potencial intensificação das condições de aridez na região central do Nordeste; mudança do clima tropical úmido para clima tropical subúmido no sul da Amazônia; e possível aumento da precipitação e da vazão na região sul do país (IPCC, 2013). Tais efeitos poderiam agravar ainda mais as condições de segurança hídrica do Brasil.

Com a criação do Sistema Nacional de Gerenciamento de Recursos Hídricos (SINGREH), por meio da Lei das Águas de 1997, foi possível iniciar uma gestão mais democrática e participativa dos recursos hídricos. No entanto, ainda existem algumas falhas de gestão (Veiga; Magrini, 2013). Um ponto que merece destaque é a desigualdade na distribuição dos Comitês de Bacia entre as regiões brasileiras. Na região Norte, apenas os estados do Amazonas e do Tocantins possuem Comitês de Bacia, 1 e 4, respectivamente. Por outro lado, todos os outros estados brasileiros nas outras regiões possuem comitês. Por exemplo, Minas Gerais tem 35, São Paulo tem 21, Bahia tem 14, Rio Grande do Sul tem 25, Goiás tem 8 (CBH, 2018). Esse fato pode ser explicado devido às grandes dimensões do país, levando os gestores a priorizar as regiões mais problemáticas, a escassez ou outros conflitos hídricos (Veiga e Magrini, 2013). Diante disso, vale ressaltar a importância de uma gestão integrada, incluindo todas as regiões brasileiras, para que toda a população possa ser atendida e seus problemas possam ser ouvidos e resolvidos de forma participativa.

Como mostrado nesta revisão, a segurança hídrica depende de diversas variáveis, como disponibilidade, qualidade e também de fatores externos, como demandas, mudanças climáticas e mudanças no uso da terra. Problemas relacionados à segurança hídrica dependem da região, de quais são as principais demandas e como o gerenciamento da água é realizado naquele local. $\mathrm{E}$ a solução será alcançada de forma participativa e levando em consideração as pessoas e o meio ambiente. Outros aspectos podem ser incluídos nesta discussão que não foram mencionados nesta revisão. 


\section{AGRADECIMENTOS}

O presente trabalho foi realizado com apoio da Coordenação de Aperfeiçoamento de Pessoal de Nível Superior - Brasil (CAPES) - Código de Financiamento 001 (Processo CAPES 88882.328917/2019-01) e do Conselho Nacional de Desenvolvimento Científico e Tecnológico CNPq (Processo 165004/2018-5).

Agradecimentos também à CAPES PROEX 1650/2017/23038.013525/2017-3; CAPES 24/2014, Pró-Alertas 88887.091743/2014-01, CEPED-USP/NAP; CNPq 465501/2014-1, FAPESP 2014/50848-9 INCT-II Mudanças Climáticas; CNPq 312056/2016-8, EESC-USP/CEMADEN/ MCTIC; FAPESP CEPID-CeMEAI 2013/07375-0, Fase 2.

\section{CONTRIBUIÇÃO DOS AUTORES}

\section{Conceitualização; Metodologia; Redação; Revi-} são \& Edição: SANTOS, A. C. e REIS, A. Aquisição de Financiamento; Recursos; Supervisão: MENDIONDO, E. M.

\section{REFERÊNCIAS}

ABES - Associação Brasileira de Engenharia Sanitária e Ambiental. Ranking 2018 da Universalização do Saneamento. Disponível em: <http://abes-dn.org.br/wp-content/uploads/2018/06/ Ranking_2018a.pdf>. Acesso em: Nov. 2018.

ANA - Agência Nacional de Águas. Divisões hidrográficas do Brasil. Disponível em: <http://www3.ana.gov.br/portal/ANA/ panorama-das-aguas/divisoes-hidrograficas $>$. Acesso em: Nov. 2018a.

ANA - Agência Nacional de Águas. 0 que é o SINGREH? Disponível em: <http://www3.ana.gov.br/portal/ANA/aguas-no-brasil/ sistema-de-gerenciamento-de-recursos-hidricos/o-que-e-o-singreh>. Acesso em: Nov. 2018b.

ANA - Agência Nacional de Águas. Conjuntura dos Recursos Hídricos no Brasil. Relatório Pleno. Brasília: ANA, 2017a.

ANA - Agência Nacional de Águas. Atlas Esgotos Despoluição de Bacias Hidrográficas. Agência Nacional de Águas, Secretaria Nacional de Saneamento Ambiental. Brasília: ANA, 2017b.

ANA - Agência Nacional de Águas. Conjuntura dos Recursos Hídricos no Brasil. Relatório Pleno. Brasília: ANA, 2013.
ANA - Agência Nacional de Águas. Conjuntura dos Recursos Hídricos no Brasil. Relatório Pleno. Brasília: ANA, 2009.

ANEEL - Agência Nacional de Energia Elétrica do Brasil. Bandeiras Tarifárias. Disponível em: <http://www.aneel.gov.br/bandeiras-tarifarias>. Acesso em: Nov. 2018.

BENTO, C. B. et al. Impacts of sugarcane agriculture expansion over low-intensity cattle ranch pasture in Brazil on greenhouse gases. Journal of Environmental Management, v. 206, p. 980988, 2018. https://doi.org/10.1016/j.jenvman.2017.11.085

BRASIL. Lei $\mathbf{n}^{\circ}$ 11.445, de 5 de janeiro de 2007. Disponível em: <http://www.planalto.gov.br/ccivil_03/_Ato2007-2010/2007/ Lei/L11445.htm>. Acesso em: Nov. 2018.

BRASIL. Ministério de Minas e Energia. Renováveis devem manter participação de $\mathbf{4 3} \%$ na matriz energética em 2017. Disponível em: <http://www.mme.gov.br/web/guest/pagina-inicial/outras-noticas/-/asset_publisher/32hLrOzMKwWb/content/renovaveis-devemmanter-participacao-de-43-na-matriz-energetica-em-2017>. Acesso em: Nov. 2018.

BRASIL. Lei n 9.433, de 8 de janeiro de 1997. Disponível em: <http://www.planalto.gov.br/ccivil_03/LEIS/L9433.htm>. Acesso em: Nov. 2018.

CASTILLO, R. M. et al. Uncovering the Green, Blue, and Grey Water Footprint and Virtual Water of Biofuel Production in Brazil: A Nexus Perspective. Open Access Sustainability, v. 9, n. 11, 2017. https://doi:10.3390/su9112049

CBD - Convention of Biological Diversity. Climate Change and Biodiversity. Disponível em: <https://www.cbd.int/climate/intro. shtml>. Acesso em: Nov. 2018.

CBH - Comitês Brasileiros de Bacias Hidrográficas. Disponível em: <http://www.cbh.gov.br/\#not-estaduais>. Acesso em: Nov. 2018.

CEMADEN, 2015. Relatório da Situação Atual e Projeção Hidrológica para o Sistema Cantareira. Disponível em: <www. cemaden.gov.br/cantareira/arquivos/Relatorio_SistemaCantareira_20150513.pdf>. Acesso em: Out. 2018.

COSGROVE, W. J.; LOUCKS, D. P. (2015) Water management: Current and future challenges and research directions. Water Resources Research, v. 51, p. 4823-4839, 2015. https:// doi:10.1002/2014WR016869

DA SILVA, V. P. R. et al. Water Footprint and Virtual Water Trade of Brazil. Water, v. 8, n. 517, 2016. https://doi:10.3390/w8110517

FAO - Food and Agriculture Organization of the United Nations. FAO no Brasil. Disponível em: <http://www.fao.org/brasil/noticias/detail-events/en/c/1098805/>. Acesso em: Nov. 2018.

FERROUKHI, R. et al. (2015). Renewable Energy in the Water, Energy \& Food Nexus. IRENA.

HILST, F. et al. Mapping land use changes resulting from biofuel production and the effect of mitigation measures. Global 
Change Biology,v. 10, p. 804-824, 2018. https://doi.org/10.1111/ gcbb. 12534

IBGE - Instituto Brasileiro de Geografia e Estatística (2017). Uso da terra. Disponível em: <https://ww2.ibge.gov.br/home/geociencias/recursosnaturais/usodaterra/default.shtm>. Acesso em: Nov. 2018.

INVEST-SP - São Paulo State Agency for the Promotion of Investments and Competitiveness. Cana-de-açúcar. Disponível em: <https://www.investe.sp.gov.br/setores-de-negocios/agronegocios/cana-de-acucar/>. Acesso em: Nov. 2018.

IPCC - Intergovernmental Panel on Climate Change. Climate Change 2013: The Physical Science Basis. Contribution of Working Group I to the Fifth Assessment Report of the Intergovernmental Panel on Climate Change. Cambridge: Cambridge University Press.

KELMAN, J. Water supply to the two largest Brazilian metropolitan regions. Aquatic Procedia, v. 5, p. 13-21, 2015. https://doi. org/10.1016/j.aqpro.2015.10.004

MARTINS, R. (2015). A seca já começou a afetar a economia. São Paulo, SP, Brasil.

MILLINGTON, N. Producing water scarcity in São Paulo, Brazil: The 2014-2015 water crisis and the binding politics of infrastructure. Political Geography, v. 65, p. 26-34, 2018. https://doi. org/10.1016/j.polgeo.2018.04.007

PLANSAB - Plano Nacional de Saneamento Básico. Ministério das Cidades, Secretaria Nacional de Saneamento Ambiental, Brasília: 2013.

RENEWPOWER (2014). Renew Power. Retrieved from Renew Power Energia no Brasil. Disponível em: <http://renewpower.com. br/wp-content/uploads/2014/06/RENEWPOWEREnergia-no-Brasil-23-3-14.pdf>. Acesso em: Nov. 2018.

RIBEIRO, M. M. R.; Lanna, A. E.; Pereira, J. S. Elasticidade-preço da demanda e a cobrança pelo uso da água. In: XIII Simpósio Brasileiro de Recursos Hídricos, 1999, Belo Horizonte. Anais...

SANTOS, F. F. S. et al. O desenvolvimento do saneamento básico no Brasil e as consequências para a saúde pública. Revista Brasileira de Meio Ambiente, v. 4, n. 1, 2018.

SEEG - Sistema de Estimativa de Emissão e Remoção de Gases de Efeito Estufa. Emissões e remoções de gases de efeito estufa no
Brasil - 2016. Disponível em: <http://seeg.eco.br/pais/ >. Access in: Nov. 2018.

SIMÃO E SILVA, F. Otimização da cobrança pelo uso da água para a gestão da demanda hídrica em cenários de longo prazo. Dissertação (Mestrado) - Escola de Engenharia de São Carlos, USP, 2009.

SPERLING, E. Hydropower in Brazil: overview of positive and negative environmental aspects. Energy Procedia, v. 18, p. 110-118, 2012. https://doi.org/10.1016/j.egypro.2012.05.023

SRINIVASAN, V.; SETO, K. C.; EMERSON, R.; GORELICK, S. M. The impact of urbanization on water vulnerability: A coupled human-environment system approach for Chennai, India. Global Environmental Change, v. 23, p. 229-239, 2013. https://doi.org/10.1016/j.gloenvcha.2012.10.002

TCU - Tribunal de Contas da União. Auditoria conclui que bandeiras tarifárias não geram consumo consciente. Disponível em: <https://portal.tcu.gov.br/imprensa/noticias/auditoria-conclui-que-bandeiras-tarifarias-nao-geram-consumo-consciente. htm>. Acesso em: Nov. 2018.

THE WORLD BANK. Recovering Water: A Results-Based Approach to Water Supply and Sanitation in Brazil's São Paulo State. Disponível em: <https://www.worldbank.org/en/results/2018/05/07/approach-to-water-supply-and-sanitation-brazil-sao-paulo-state>. Acesso em: Out. 2018.

UN - United Nation. The Sustainable Development Goals 2030 Agenda. Disponível em: <https://sustainabledevelopment. un.org/>. Acesso em: Nov. 2018.

UN-WATER, 2018. Water and Climate Change. Disponível em: < http://www.unwater.org/water-facts/climate-change/>. Acesso em: Nov. 2018.

UN-WATER, 2013. Water Security and the Global Water Agenda: A UN-Water Analytical Brief. UN University, Hamilton, ON.

VEIGA, L. B. E.; MAGRINI, A. The Brazilian Water Resources Management Policy: Fifteen Years of Success and Challenges. Water Resources Management, v. 27, n. 7, p. 2287-2302, 2013. https:// doi.org/10.1007/s11269-013-0288-1

WHO, W. H. (2012). WHO Library Cataloguing-in-Publication Data. World Health Organization, Paris. 